\title{
Control of the degradation of silica sol-gel hybrid coatings for metal implants prepared by the triple combination of alkoxysilanes
}

F. Romero-Gavilán ${ }^{\mathrm{a}}$, S. Barros-Silva ${ }^{\mathrm{a}}$, J. García-Cañadas ${ }^{\mathrm{a}^{*}}$, B. Palla ${ }^{\mathrm{b}}$, R. Izquierdo ${ }^{\mathrm{a}}$, M. Gurruchaga ${ }^{\mathrm{b}}$, I. Goñi ${ }^{\mathrm{b}}$, J. Suay ${ }^{\mathrm{a}}$

aDepartamento de Ingeniería de Sistemas Industriales y Diseño. Universitat Jaume I, Av. Vicent Sos Baynat s/n. Castellón 12071. Spain.

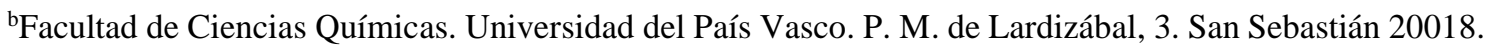
Spain.

*Corresponding author: garciaj@uji.es 


\begin{abstract}
Hybrid materials obtained by sol-gel process are able to degrade and release Si compounds that are useful in regenerative medicine due to their osteoinductive properties. The present work studies the behavior of new organic-inorganic sol-gel coatings based on triple mixtures of alkoxysilanes in different molar ratios. The precursors employed are methyl-trimethoxysilane (MTMOS), 3-glycidoxypropyl-trimethoxysilane (GPTMS) and tetraethyl-orthosilicate (TEOS). After optimization of the synthesis conditions, the coatings were characterized using ${ }^{29} \mathrm{Si}$ nuclear magnetic resonance $\left({ }^{29} \mathrm{Si}-\mathrm{MNR}\right)$, Fourier transform infrared spectrometry (FT-IR), contact angle measurements, hydrolytic degradation assays, electrochemical impedance spectroscopy (EIS) and mechanical profilometry. The degradation and EIS results show that by controlling the amount of TEOS precursor in the coating it is possible to tune its degradation by hydrolysis, while keeping properties such as wettability at their optimum values for biomaterials application. The corrosion properties of the new coatings were also evaluated when applied to stainless steel substrate. The coatings showed an improvement of the anticorrosive properties of the steel which is important to protect the metal implants at the early stages of the regeneration process.
\end{abstract}

Keywords: Si release, corrosion resistance, TEOS, biomaterials, coatings 


\section{Introduction}

In implantology, metal implants are the most frequently used materials, being titanium and its alloys the most widely used. This is due to their low density, high resistance to corrosion, good mechanical properties and its biocompatibility [1]. However, these materials are bio-inert and damage in their protective oxide layer that provides their corrosion resistive properties, can produce implant failure. Studies about implants failure suggest that some of the faults may be due to the diffusion of corrosion products through the surrounding tissues as a result of the degradation of the titanium dioxide layer [2,3]. Another problem in the use of titanium as an implant is its high cost, which is the reason behind the still significant demand for surgical grade stainless steel implants in some countries. Stainless steel possesses worse properties and a higher risk of failure than titanium [4]. Both, the need to protect the metal to prevent the release of corrosion products and the functionalization of metal implants surface in order to improve their biological interaction are required for the development of new implant coatings.

The sol-gel technique allows developing coatings in a relatively inexpensive way which confers the implant surface the desired properties by means of an appropriate selection of precursors and the optimization of the synthesis parameters. These coatings are biocompatible, able to release $\mathrm{Si}$ compounds with osteoinductive properties, protecting the implant against corrosion, and enable the functionalization of the metal surface to achieve the desired cellular response to improve tissue regeneration [5-9].

Within the sol-gel materials, there is a growing interest in organic-inorganic silicon materials synthesized via sol-gel [10]. For this reason this work focuses on the implant surface bioactivation via hybrid sol-gel coatings from alkoxysilanes, which are used due to their possibility to more easily regulate key properties such as the hydrophilic behavior and degradability [11]. These materials have already been used in biomedical applications due to their osteoinductive capabilities [12,13], as delivery vehicles of drugs $[14,15]$, or as antibacterial agents to enhance the strength of implants to yeast infections $[16,17]$.

This osteoinductive capability of the hybrid sol-gel materials is attributed to their ability to release silicon compounds during the hydrolytic degradation of the sol-gel network [7,18]. Silicon is an essential element for the metabolic processes associated with the formation and calcification of bone [19]. It develops a biological crosslinking agent role, which contributes to the resistance architecture and connective tissues [20]. In addition, the presence of $\mathrm{Si}$ in the $\mathrm{Si}(\mathrm{OH})_{4}$ form promotes the synthesis of collagen type I and enhances osteoblastic differentiation [20,21]. Consequently, the degradation control is a way to regulate the bioactivity degree of coatings.

Ballarre et al. developed hybrid sol-gel coatings based on the combination of several layers on surgical grade stainless steel to enhance their anticorrosive properties, demonstrating their protective capabilities [22]. Catauro et al. succeeded in improving the bioactivity and biocompatibility of grade 4 titanium dental implants by employing sol-gel hybrid coatings synthesized from polyethylene glycol (PEG) and TEOS in different ratios [13]. Juan-Diaz et al. developed hybrid sol-gel coatings, using methyl-trimethoxysilane (MTMOS) and TEOS as alkoxysilanes in 10:0, 9:1, 8:2 and 7:3 molar ratios and studied their degradation. This characterization suggested the ability to regulate the degradation of such materials by modifying their composition in order to design suitable controlled-released vehicles [14]. Another research study developed 
hybrid sol-gel coatings with different percentages of MTMOS and 3-glycidoxypropyl-trimethoxysilane (GPTMS) as precursors to enhance the osseointegration ability of titanium dental implants [18]. These materials showed a good in vitro behavior with an improvement in the proliferation and mineralization respect to titanium, being this effect more pronounced for the 1:1 MTMOS:GPTMS ratio. However, the in vivo response was not as good as was expected due to the formation of a fibrous capsule, probably as a consequence of the poor degradation kinetics.

The aim of this work is the development of organic-inorganic sol-gel coatings through triple-precursor compositions based on the combination of alkoxysilanes (MTMOS, GPTMS and TEOS). The addition of TEOS into MTMOS:GPTMS coatings, which already show a good in vitro behavior [18] is expected to allow the control of the degradation kinetics and hence improve the osseointegration ability of metallic implants. Simultaneously, the coating should protect the implant during the first stage post-implantation, being then necessary a balance between degradation and protection. The study of this compromise is conducted by hydrolytic degradation and electrochemical impedance spectroscopy (EIS) tests.

\section{Materials and methods}

Sol-gel synthesis

The synthesis process of the hybrid coatings was based in a sol-gel route employing MTMOS (SigmaAldrich), TEOS (Sigma-Aldrich) and GPTMS (Sigma-Aldrich) as precursors. Different compositions of these precursors were used as shown in Table 1. 2-Propanol (Sigma-Aldrich) was used in the process to improve the mixing of the siloxanes in a volume ratio alcohol:siloxane 1:1. Precursor hydrolysis was performed by adding the corresponding stoichiometric amount of an acidified aqueous solution $0.1 \mathrm{M} \mathrm{HNO}_{3}$ (Panreac) to catalyze the reaction. The solution was kept $1 \mathrm{~h}$ under stirring and then $1 \mathrm{~h}$ at rest. The samples were prepared from the corresponding sol-gel solution immediately after this time.

Table 1. Molar percentage of the materials under study.

\begin{tabular}{llll} 
& MTMOS $(\%)$ & GPTMS $(\%)$ & TEOS $(\%)$ \\
$50 \mathrm{M} 50 \mathrm{G}$ & 50 & 50 & 0 \\
\hline $55 \mathrm{M} 45 \mathrm{G} 10 \mathrm{~T}$ & 45 & 45 & 10 \\
35M35G30T & 35 & 35 & 30 \\
$25 \mathrm{M} 25 \mathrm{G} 50 \mathrm{~T}$ & 25 & 25 & 50 \\
$15 \mathrm{M} 15 \mathrm{G} 70 \mathrm{~T}$ & 15 & 15 & 70 \\
$5 \mathrm{M} 5 \mathrm{G} 90 \mathrm{~T}$ & 5 & 5 & 90
\end{tabular}




\section{Coatings preparation}

Three different processes were adopted for the sample preparation as required by the different characterization methods. Firstly, AISI 316-L stainless steel plates ( $5 \mathrm{~cm}$ x $5 \mathrm{~cm}$, RNSinox S.L.) were used as substrates. The surfaces of the plates were polished and then cleaned with acetone to remove impurities. After cleaning, the film deposition was performed employing a dip-coater (KSV instrument-KSV DC). Plates were immersed into the previously prepared sol-gel solutions at a speed of $60 \mathrm{~cm} \mathrm{~min}^{-1}$, then kept immersed for one minute, and finally they were removed at a $100 \mathrm{~cm} \cdot \mathrm{min}^{-1}$ speed. After the corresponding heat treatment (table 2), the adhesion was evaluated by means of the cross-cut test (UNE EN-ISO 2409:2013). Once proved that the highest adherence value, i.e. 0, was obtained, the thickness of the coatings prepared was measured by mechanical profilometry (Dektack 6, Veeco). Two distinct samples identically prepared were tested, performing 3 measurements per sample.

Secondly, glass slides were used as substrates of the coatings. The glass surfaces were previously cleaned in an ultrasonic bath (Sonoplus HD 3200) for $20 \mathrm{~min}$ at $30 \mathrm{~W}$ with nitric acid solution at $25 \%$ volume. Then a further cleaning was carried out with distilled water under the same conditions. After being dried at $100{ }^{\circ} \mathrm{C}$, the glass slides were coated by the flow-coating technique.

Finally, free films of materials were obtained by pouring the sol-gel solutions into non-stick Teflon molds. Samples were cured under the conditions described in Table 2, which shows the minimum temperatures required to obtain homogeneous and well-cured films.

Table 2. Heat treatment conditions applied to each sol-gel composition.

\begin{tabular}{|c|c|c|c|c|c|c|}
\hline Composition & $50 \mathrm{M} 50 \mathrm{G}$ & $45 \mathrm{M} 45 \mathrm{G} 10 \mathrm{~T}$ & 35M35G30T & 25M25G50T & $15 \mathrm{M} 15 \mathrm{G} 70 \mathrm{~T}$ & 5M5G90T \\
\hline $\begin{array}{l}\text { Curing } \\
\text { temperature } \\
\left({ }^{\circ} \mathrm{C}\right)\end{array}$ & 140 & 100 & 80 & 80 & 80 & 80 \\
\hline $\begin{array}{l}\text { Curing time } \\
\text { (min) }\end{array}$ & 120 & 120 & 120 & 120 & 120 & 120 \\
\hline
\end{tabular}

\section{Chemical characterization}

Attenuated total reflection (ATR) analysis was performed on the free film samples using a Fouriertransform infrared spectrometer (Model FTIR 6700, NICOLET) to analyze the chemical composition of the sol-gel materials. Before each measurement, a background FTIR spectrum was taken and deducted from the sample spectra. All spectra were recorded in the $600-4000 \mathrm{~cm}^{-1}$ wavelength range.

Solid-state ${ }^{29} \mathrm{Si}-\mathrm{NMR}$ spectroscopy was used to evaluate the crosslinking density of the silicon network after the thermal processing. Free films were used for this purpose. The spectra were obtained using a Bruker 400 AVANCE II WB Plus spectrometer, equipped with a Cross Polarization Magic Angle Spinning (CP-MAS) probe. The samples were placed inside a $4 \mathrm{~mm}$ rotor sample tube. The spinning speed was 7.0 
kHz. The pulse sequence employed was the Bruker standard: $79.5 \mathrm{MHz}$ frequency, spectral width of 55 $\mathrm{KHz}, 2 \mathrm{~ms}$ contact time and $5 \mathrm{~s}$ delay time.

\section{Physico-chemical characterization}

The wettability of the sol-gel coating was determined by the measurement of the contact angle. An automatic contact angle meter (Dataphysics OCA 20) was used to measure this parameter. $10 \mu \mathrm{L}$ of ultrapure water were deposited on the hybrid sol-gel coated steel plates at room temperature. The drops were formed with a dossing rate of $27.5 \mu \mathrm{Ls}^{-1}$ and the angles were determined with the aid of SCA 20 software. Reported values are the average of 60 measurements obtained at different spots of three different samples identically prepared.

Roughness of the material on coated steel plates was assessed using a mechanical profilometer Dektack 6 (Veeco). Three individual measurements were performed to obtain each value.

The anticorrosive properties of the sol-gel coatings were evaluated by EIS measurements, which were carried out on the samples deposited on the steel substrates at different exposure times to $3.5 \% \mathrm{wt}$. $\mathrm{NaCl}$ in deionized water for up to $48 \mathrm{~h}$. The exposure surface area was $3.14 \mathrm{~cm}^{2}$. A three-electrode electrochemical cell was employed. The sample without coating acted as the working electrode, a $\mathrm{Ag} / \mathrm{AgCl}$ electrode was used as reference and a graphite sheet was employed as counter-electrode. Measurements were obtained using an Autolab Ecochemie PGSTAT30 potentiostat equipped with a frequency response analyzer module. The tests were conducted at the free corrosion potential. A frequency range from $10 \mathrm{mHz}$ to $100 \mathrm{kHz}$ with a sinusoidal voltage perturbation of $10 \mathrm{mV}$ amplitude was applied to the system. Experiments were performed inside a Faraday cage in order to minimize external interference. Measurements were carried out at $0,1.5,3,4,6,8,10,24$ and $48 \mathrm{~h}$ of exposure at room temperature. All tests were repeated at least three times in order to check reproducibility. Two equal results are considered valid and the results shown are from the most representative sample.

The hydrolytic degradation of the coatings was evaluated using the materials deposited on glass slides. The kinetics of degradation was determined by means of the weight loss in the samples before and after soaking in $100 \mathrm{~mL}$ distilled water at $37^{\circ} \mathrm{C}$ for periods of 7, 14, 28, 42 and 63 days. The samples were dried in a vacuum oven at $37^{\circ} \mathrm{C}$ for $48 \mathrm{~h}$ before and after soaking. Each data point is the mean of three measurements performed in three different samples identically prepared. 


\section{Results}

\section{Chemical characterization}

The degree of condensation of the materials synthesized from the alkoxysilanes was studied by ${ }^{29} \mathrm{Si}$ solid NMR. The nomenclature used in the analysis of the results was described in reference [23]. $\mathrm{T}^{\mathrm{n}}$ and $\mathrm{Q}^{\mathrm{n}}$ represents the trifunctional and tetrafunctional silicon, respectively, while the superscript $\mathrm{n}$ shows the number of bonded oxygens to silicon. Fig. 1 shows the NMR spectra of the fabricated films. For the composition 50M50G, the signal associated to $\mathrm{T}^{1}, \mathrm{~T}^{2}$ and $\mathrm{T}^{3}$ species can be observed, being the most intense and the weakest the signals with two $\left(\mathrm{T}^{2}\right)$ and only one $\left(\mathrm{T}^{1}\right)$ oxygens bonded to the silicon atom, respectively. It should be mentioned that the recorded signal for the 50M50G spectrum only covers the -40 to $-80 \mathrm{ppm}$ chemical shift range since no response is usually observed for chemical shifts more negative than -80 ppm [18].

The NMR spectra when TEOS precursor is introduced in the films are also given in Fig. 1 (spectra $b$ to $f$ ). These spectra, apart from $\mathrm{T}^{\mathrm{n}}$ species from MTMOS and GPTMS, show $\mathrm{Q}^{2}, \mathrm{Q}^{3}$ and $\mathrm{Q}^{4}$ signals from TEOS. When the ratio of TEOS is increased it is observed that the signals $\mathrm{Q}^{\mathrm{n}}$ become more intense and $\mathrm{T}^{\mathrm{n}}$ are attenuated, due to the reduced number of MTMOS and GPTMS species in the sol-gel network. The addition of TEOS causes the almost total suppression of $\mathrm{T}^{1}$ signal and the intensity increase of $\mathrm{T}^{3}$ peak, especially at low TEOS content (spectra $\mathrm{b}$ and $\mathrm{c}$ ). Thus, in materials 45M45G10T and 35M35G30T the intensity of the signals from $\mathrm{T}^{2}$ species is quite similar to $\mathrm{T}^{3}$ (spectra $\mathrm{b}$ and $\mathrm{c}$ in Fig.1). However, when the percentage of TEOS increases, $\mathrm{T}^{2}$ becomes more intense than $\mathrm{T}^{3}$ (spectra $\mathrm{d}$, e and $\mathrm{f}$ ) and $\mathrm{Q}^{2}$ increases respect to $\mathrm{Q}^{4}$ (spectra e and f).

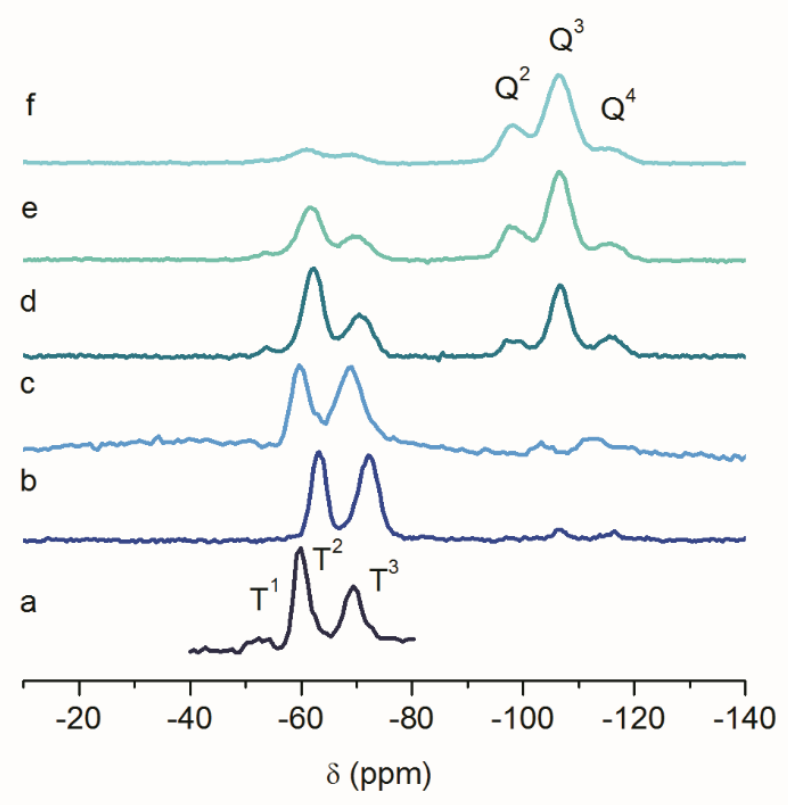

Fig. 1. ${ }^{29} \mathrm{Si}$ solid NMR of (a) 50M50G, (b) 45M45G10T, (c) 35M35G30T, (d) 25M25G50T, (e) 15M15G70T and (f) 5M5G90T films. 
Fig. 2 shows the IR spectra of the sol-gel networks. The bands associated with the vibrational modes of the Si-O-Si chains were detected at $\sim 780, \sim 1010$ and $\sim 1100 \mathrm{~cm}^{-1}$, which are due to the formation of the inorganic network $[24,25]$. The bands related to the vibrational modes of OH groups $\left(3200-3500 \mathrm{~cm}^{-1}\right)$ and Si-OH terminals $\left(\sim 890 \mathrm{~cm}^{-1}\right)$ were also observed [24,25]. The bands detected between 2870 and $2950 \mathrm{~cm}^{-}$ ${ }^{1}$ indicate the presence of $\mathrm{C}-\mathrm{H}$ bonds and the band at $\sim 1265 \mathrm{~cm}^{-1}$ correspond to Si-C [25]. All these signals show the presence of organic matter introduced through the MTMOS and GPTMS precursors. These signals become less intense in those materials with the highest proportion of TEOS and nearly disappear for the 5M5G90T composition (spectrum f).

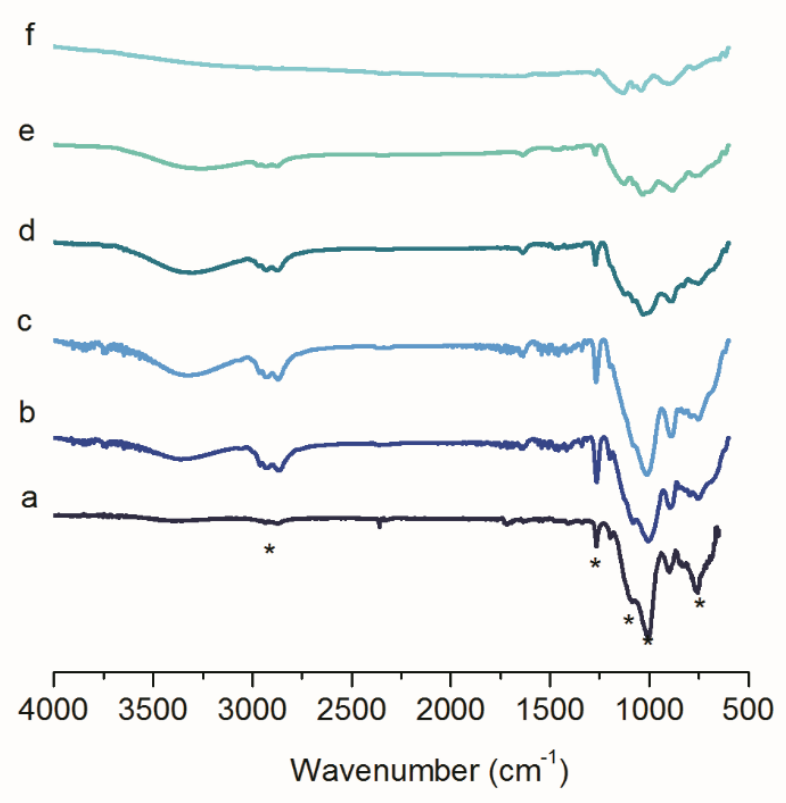

Fig. 2. FTIR spectra of (a) 50M50G, (b) 45M45G10T, (c) 35M35G30T, (d) 25M25G50T, (e) 15M15G70T and (f) 5M5G90T films.

\section{Contact angle}

The wettability of the formulations was studied by means of contact angle measurements. Results are shown in Fig. 3. It is observed that the addition of TEOS to the sol-gel network in moderate amounts decreases the contact angle, i.e., the material becomes more hydrophilic. However, the contact angle increases after reaching a minimum for the $30 \%$ TEOS film when the TEOS percentage is increased further. 


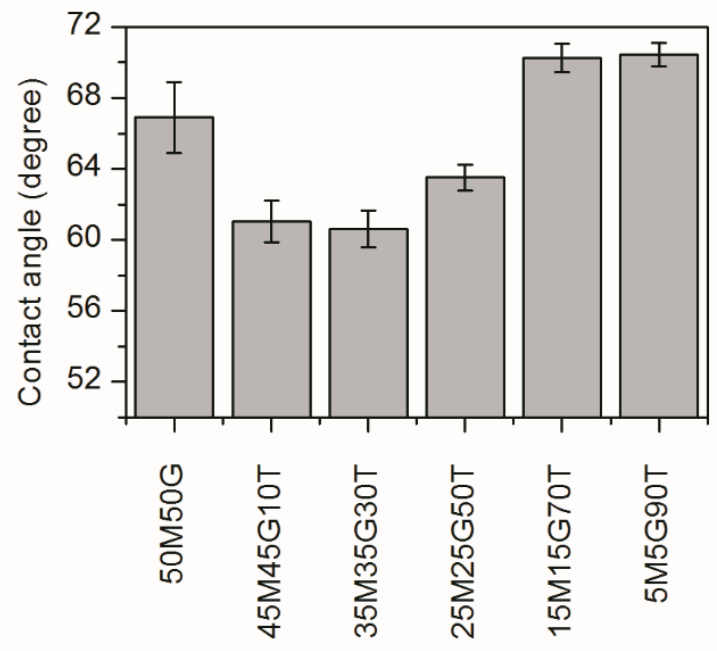

Fig. 3. Contact angle results for films deposited on stainless steel substrates with different MTMOS:GPTMS:TEOS molar ratios. Bars indicate standard deviations.

\section{Morphological characterization}

Fig. 4 shows the coating thickness measurements. When is added up to $70 \%$ of TEOS, the coating thicknesses have a value between $0.87-1.18 \mu \mathrm{m}$ without statistically significant differences between them. However, the 5M5G90T composition shows a markedly smaller thickness compared with the other materials.

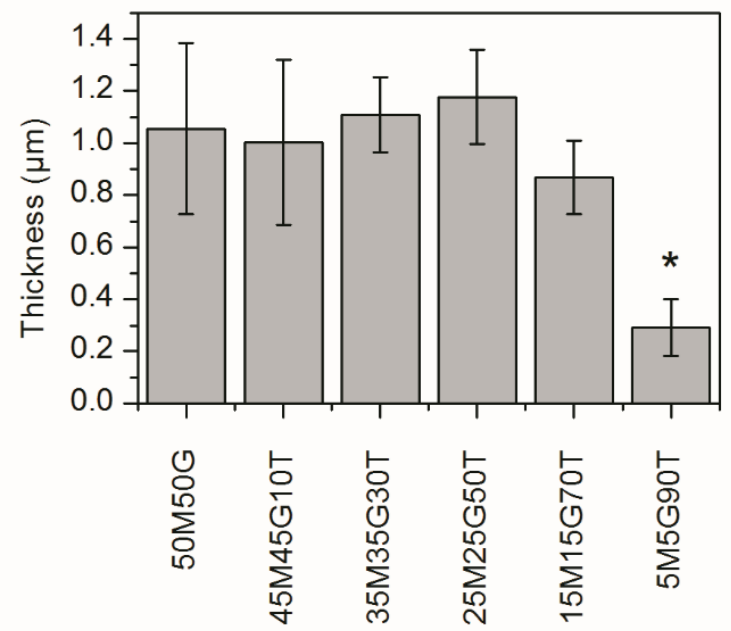

Fig. 4. Coating thickness of sol-gel coatings prepared onto stainless steel plates by dip-coating. $(*)$ Statistically significant differences were found in the 5M5G90T coating thickness respect the other materials (ANOVA, $\mathrm{p}<0.05)$. Bars indicate the standard deviations.

Table 3 shows the average surface roughness values $(\mathrm{Ra})$ and their standard deviations. The reference material 50M50G shows a Ra value of $288.7 \pm 73.1 \AA$. When TEOS is introduced into the structure, it is observed that Ra increases to a maximum $(788.5 \pm 3.5 \AA)$ for the 35M35G30T composition. However, 
further TEOS addition produces a less rough surface and a value of $475.7 \pm 81.7 \AA$ is reached for 5M5G90T composition.

Table 3. Ra values and their standard deviations for steel plates coated with MTMOS:GPTMS:TEOS materials in different ratios.

$\begin{array}{ll}\text { Material } & \mathrm{Ra}(\AA) \\ \text { 50M50G } & 288.7 \pm 73.1 \\ \text { 45M45G10T } & 659.5 \pm 50.2 \\ \text { 35M35G30T } & 788.5 \pm 3.5 \\ \text { 25M25G50T } & 646.3 \pm 33.3 \\ \text { 15M15G70T } & 496.7 \pm 26.8 \\ \text { 5M5G90T } & 475.7 \pm 81.7\end{array}$

EIS

Stainless steel plates were coated with 50M50G, 45M45G10T, 35M35G30T, 25M25G50T, 15M15G70T and 5M5G90T materials to perform the EIS tests. After $48 \mathrm{~h}$ of testing, the coatings showed degradation signs, being this more significant in the case of the compositions with higher TEOS percentages (70\% and 90\%). Fig. 5 shows the results obtained. It is observed that the impedance values decrease when TEOS is added in the sol-gel network (Fig. 5a). It should be noted that the variation in the impedance module values with time is less significant at the highest TEOS content, reaching nearly no variation (Fig. 5a) for the films with the highest TEOS composition. Despite the introduction of this precursor in the sol-gel structure both impedance module and phase angle maintain a similar shape to the plot obtained for the 50M50G material, so no additional process is introduced by the presence of TEOS. 

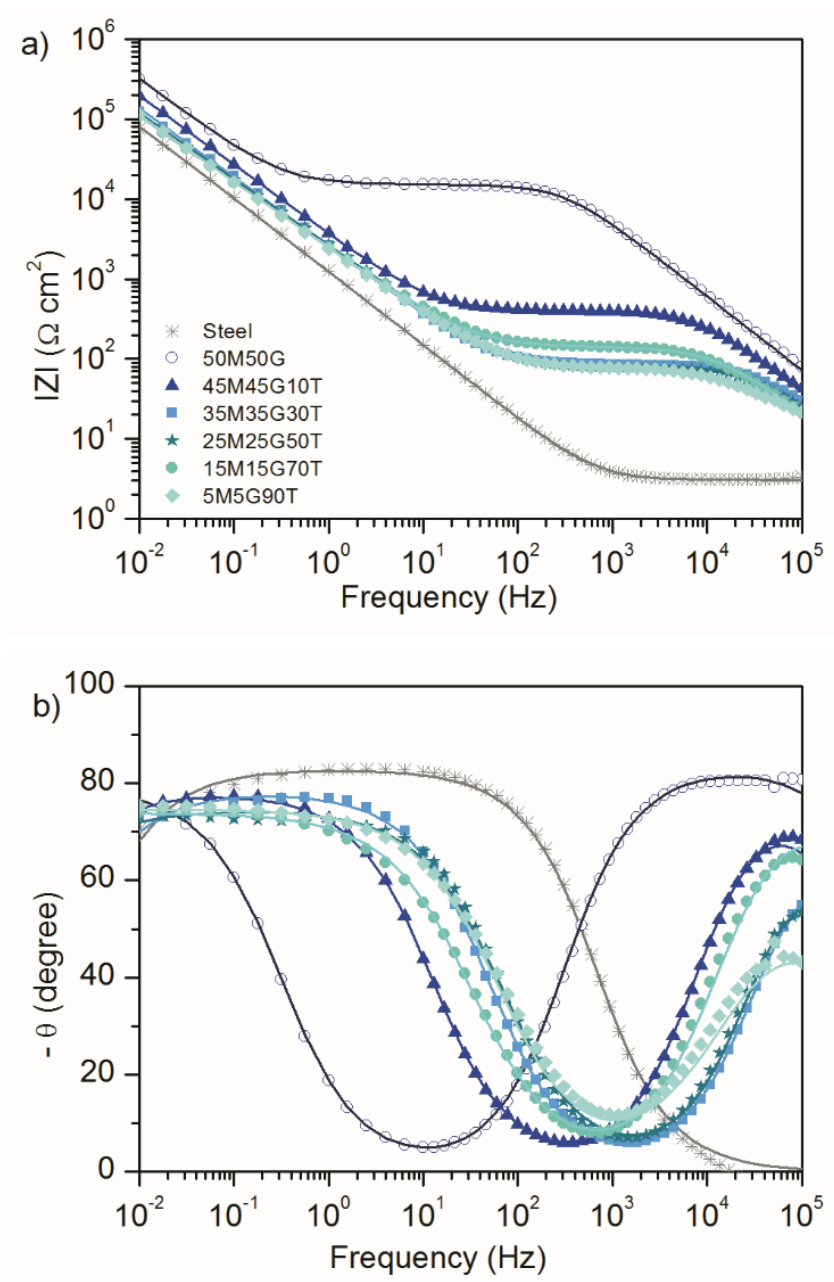

Fig. 5. (a) Impedance modules and (b) phase angel bode plots for stainless steel, 50M50G, 45M45G10T, 35M35G30T, 25M25G50T, 15M15G70T and 5M5G90T sol-gel coatings at $8 \mathrm{~h}$ of immersion in the electrolyte. Fitted results are represented by the solid lines.

The EIS spectra were fitted to equivalent circuits using Z-view software. For the coating with bare stainless steel only the natural formation of the oxide layer in the steel was observed. However, samples with solgel coatings present two processes, the first one related to the coating at high frequencies and the other at low frequencies to do with the native oxide layer. Therefore, the coating free system was fitted with an equivalent circuit of one time constant (Fig. 6a) and two time constants were employed for coated samples (Fig. 6b). This type of equivalent circuits are widely used by many authors $[9,11,14,26-28]$.

a)

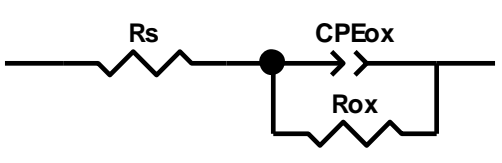

b)

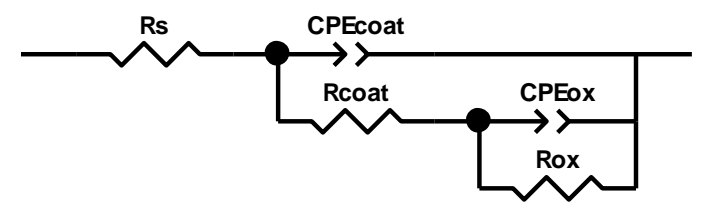

Fig. 6. Equivalent circuits used for (a) non-coated and (b) coated stainless steel substrates. They correspond to the presence of one and two time constants, respectively. 
In the model of Fig. 6a, Rox and CPEox correspond to the oxide layer. In Fig. $6 \mathrm{~b}$ the coating response is added in Rcoat and CPEcoat. By fitting the EIS data to the equivalent circuits information about the corrosion properties of the system can be extracted from the parameters obtained [29-31]. Rcoat can be related to the porosity and the deterioration of the coating and allows to study the deterioration of the solgel materials, hence, its capability to protect the metal. The CPEcoat is related to the water absorption. Rs is the electrolyte resistance.

The CPE equivalent circuit element provides values in $\mathrm{s}^{\mathrm{n}} \Omega^{-1}$ units, being $\mathrm{n}$ an exponent which is fitted. Capacitance values, in F units, can be obtained when $\mathrm{n}$ is known [32]. All fittings were quite good (Chisquared<0.01) as observed in Fig. 5.

It should be mentioned that in some systems with two time constants, the second time constant signal appears at such low frequencies that it is not possible to obtain all the characteristic parameters for the measured frequency range. In any case, as the aim of these measurements is to study the process of coating degradation, the attention is more focused on the representative parameters of this process (Rcoat and CPEcoat). Fig. 7 and 8 show the values of Rcoat and CPEcoat from the coating and Rox and CPEox from the oxide layer, respectively. As CPE elements were used instead of pure capacitors, the values of the parameter $\mathrm{n}$ are given in Table 4 .
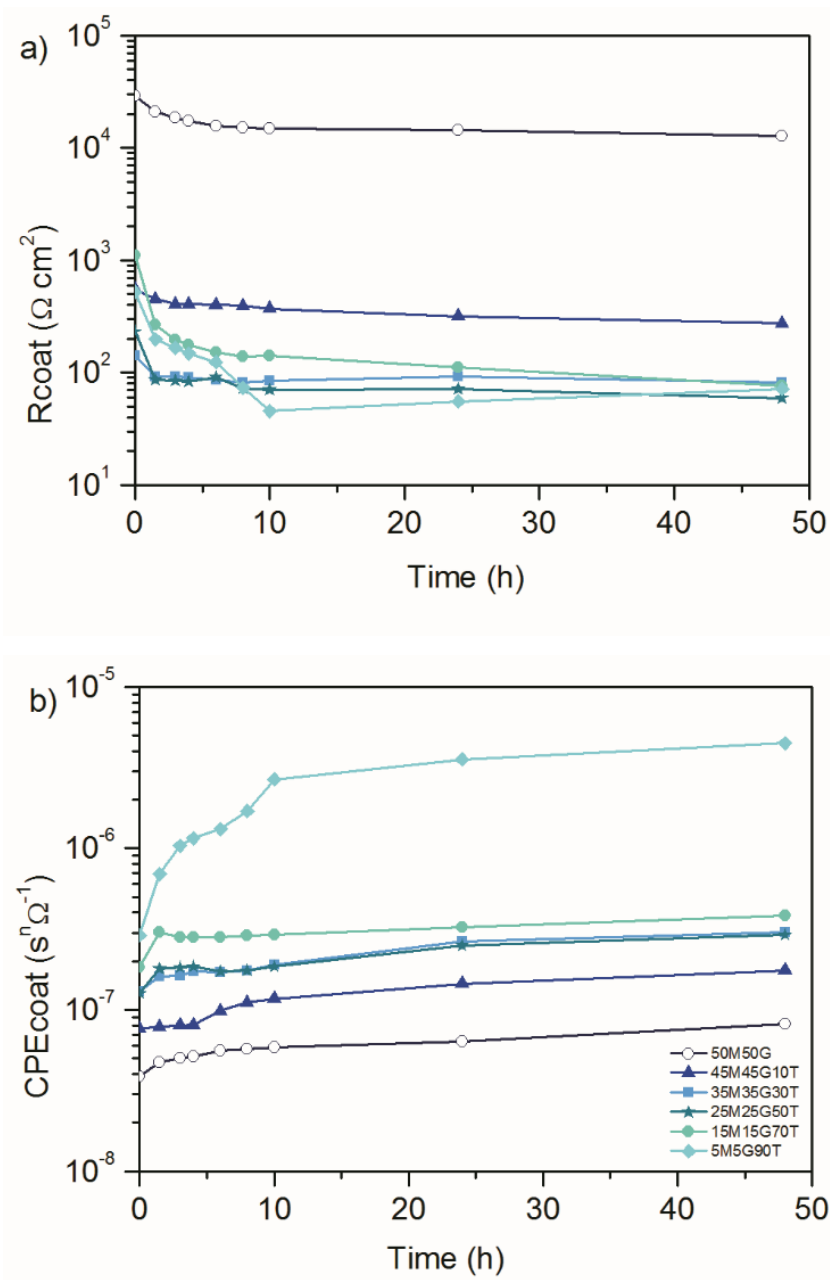
Fig. 7. Evolution of (a) Rcoat and (b) CPEcoat along the time of contact with electrolyte (3.5\% wt. $\mathrm{NaCl})$ for 50M50G, 45M45G10T, 35M35G30T, 25M25G50T, 15M15G70T and 5M5G90T coatings.

Fig. 7a shows the evolution of Rcoat with the exposure time. This parameter decreases with time, more significantly at shorter times, until a nearly constant value is achieved. This is due to the degradation of the coatings by hydrolysis. When TEOS is added to the coating, a significant decrease of Rcoat was observed (see Fig. 7a). When the presence of TEOS is increased further, Rcoat continues decreasing but more monotonically. The distinct behavior between materials may result from different initial porosity of the coatings, which can be produced by changes in the compositions. For the case of the 5M5G90T film, the different thickness could also influence. In some curves of Fig. 7a it can be seen that the value of Rcoat increases with time, this could be due to the formation of deposits that clog the pores of the coating [31].

CPE parameters are directly related with $\mathrm{Cc}$, which represents the capacitance of the coating and relates to the permeability to water penetration as $[11,14]$.

$C c=\varepsilon \varepsilon_{0} A / d$

where $\varepsilon$ is the dielectric constant of the material, $\varepsilon_{0}$ the permittivity of vacuum, $A$ is the area of coating in contact with the electrolyte and $d$ is the thickness. Increasing the value of Cc can be correlated directly with the increase in permittivity by the Equation 1. Hence, the behavior of the capacitance allows studying water absorption by the coating. In Fig. $7 \mathrm{~b}$ it is shown that the CPE value increases with the exposure time to the electrolyte in all cases. In the initial stage, this increase is more intense which could be due to initial water absorption in the coating [18]. At the longest times, the higher value of CPE observed is associated to the degradation of the sol-gel network, which facilitates the penetration of water. This behavior was also observed in MTES:TEOS coatings and was related to a decrease of organic groups that introduces a more hydrophobic character and provides more resistive capabilities to the film [5].

Fig. 8 shows the evolution of Rox and CPEox, which are representative parameters of the dielectric properties of the oxide layer. Rox increased during the early stages of exposure (Fig. 8a). At the same time, CPEox decreased, except for the bare substrate (Fig. 8b). This might be due to the passivation of steel by the formation of chrome oxides as a result of the presence of dissolved oxygen in the electrolyte [33]. At longer exposure times Rox and CPEox values remain nearly constant, showing that the oxide layer becomes quite stable. An increase of Rox and a decrease of CPEox are observed respect to the bare steel substrate when the coating is applied, showing an increase of the steel passivation. 

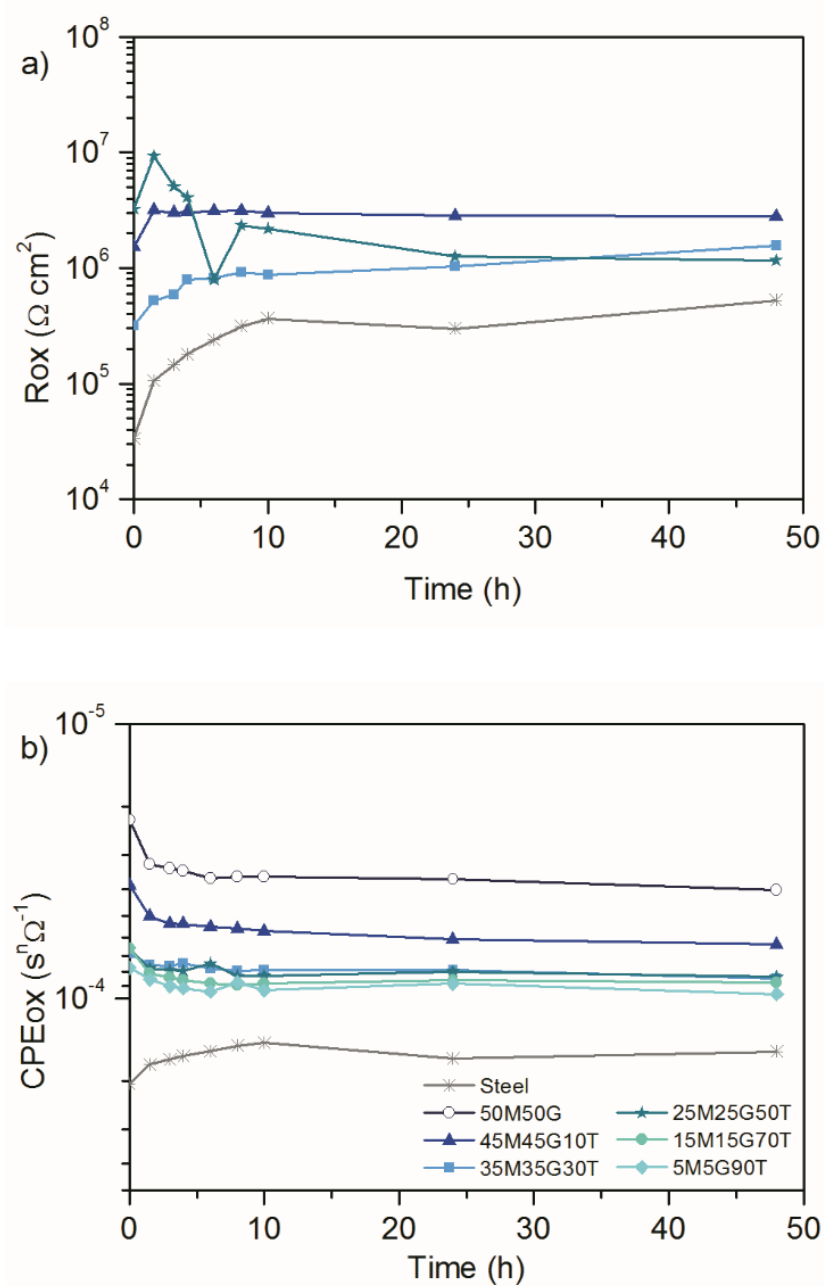

Fig. 8. Evolution of Rox (a) and CPEox (b) versus time of contact with electrolyte (3.5\% wt. NaCl) for Stainless steel, 50M50G, 45M45G10T, 35M35G30T, 25M25G50T, 15M15G70T and 5M5G90T coatings. 
Table 4. Parameters $n_{1}$ and $n_{2}$ of CPEcoat and CPEox elements, respectively, for each formulation and measuring time.

\begin{tabular}{|c|c|c|c|c|c|c|c|c|c|c|}
\hline Material & $\mathrm{n}$ & $0 \mathrm{~h}$ & $1.5 \mathrm{~h}$ & $3 \mathrm{~h}$ & $4 \mathrm{~h}$ & $6 \mathrm{~h}$ & $8 \mathrm{~h}$ & $10 \mathrm{~h}$ & $24 \mathrm{~h}$ & $48 \mathrm{~h}$ \\
\hline Stainless steel & $\mathrm{n}_{2}$ & 0.89 & 0.91 & 0.91 & 0.92 & 0.92 & 0.92 & 0.92 & 0.92 & 0.93 \\
\hline \multirow[t]{2}{*}{$50 \mathrm{M} 50 \mathrm{G}$} & $\mathrm{n}_{1}$ & 0.95 & 0.94 & 0.94 & 0.93 & 0.93 & 0.93 & 0.92 & 0.92 & 0.90 \\
\hline & $\mathrm{n}_{2}$ & 0.81 & 0.85 & 0.86 & 0.87 & 0.87 & 0.88 & 0.88 & 0.89 & 0.89 \\
\hline \multirow[t]{2}{*}{ 45M45G10T } & $\mathrm{n}_{1}$ & 0.94 & 0.94 & 0.94 & 0.94 & 0.93 & 0.93 & 0.92 & 0.91 & 0.89 \\
\hline & $\mathrm{n}_{2}$ & 0.83 & 0.86 & 0.86 & 0.87 & 0.87 & 0.87 & 0.88 & 0.89 & 0.90 \\
\hline \multirow[t]{2}{*}{ 35M35G30T } & $\mathrm{n}_{1}$ & 0.93 & 0.91 & 0.91 & 0.91 & 0.91 & 0.91 & 0.90 & 0.87 & 0.86 \\
\hline & $\mathrm{n}_{2}$ & 0.81 & 0.85 & 0.86 & 0.86 & 0.87 & 0.87 & 0.87 & 0.90 & 0.90 \\
\hline \multirow[t]{2}{*}{ 25M25G50T } & $\mathrm{n}_{1}$ & 0.95 & 0.93 & 0.92 & 0.92 & 0.91 & 0.93 & 0.93 & 0.90 & 0.89 \\
\hline & $\mathrm{n}_{2}$ & 0.78 & 0.81 & 0.82 & 0.82 & 0.86 & 0.83 & 0.83 & 0.85 & 0.87 \\
\hline \multirow[t]{2}{*}{ 15M15G70T } & $\mathrm{n}_{1}$ & 0.93 & 0.90 & 0.90 & 0.91 & 0.91 & 0.90 & 0.90 & 0.90 & 0.89 \\
\hline & $\mathrm{n}_{2}$ & 0.79 & 0.80 & 0.81 & 0.81 & 0.81 & 0.82 & 0.82 & 0.83 & 0.84 \\
\hline \multirow[t]{2}{*}{ 5M5G90T } & $\mathrm{n}_{1}$ & 0.91 & 0.85 & 0.82 & 0.81 & 0.80 & 0.78 & 0.77 & 0.74 & 0.73 \\
\hline & $\mathrm{n}_{2}$ & 0.80 & 0.80 & 0.81 & 0.81 & 0.81 & 0.83 & 0.83 & 0.84 & 0.84 \\
\hline
\end{tabular}

\section{Hydrolytic degradation}

The polysiloxane network degrades in contact with water by hydrolysis following the reaction $[11,14]$,

$\mathrm{SiO}_{2}(\mathrm{~s})+2 \mathrm{H}_{2} \mathrm{O} \leftrightarrow \mathrm{Si}(\mathrm{OH})_{4}(\mathrm{aq})$

In Fig. 9, the evolution with time of the degradation curves (weight loss) is shown. It is observed that in all cases the materials degrade, however, the kinetics of degradation depends on the composition.

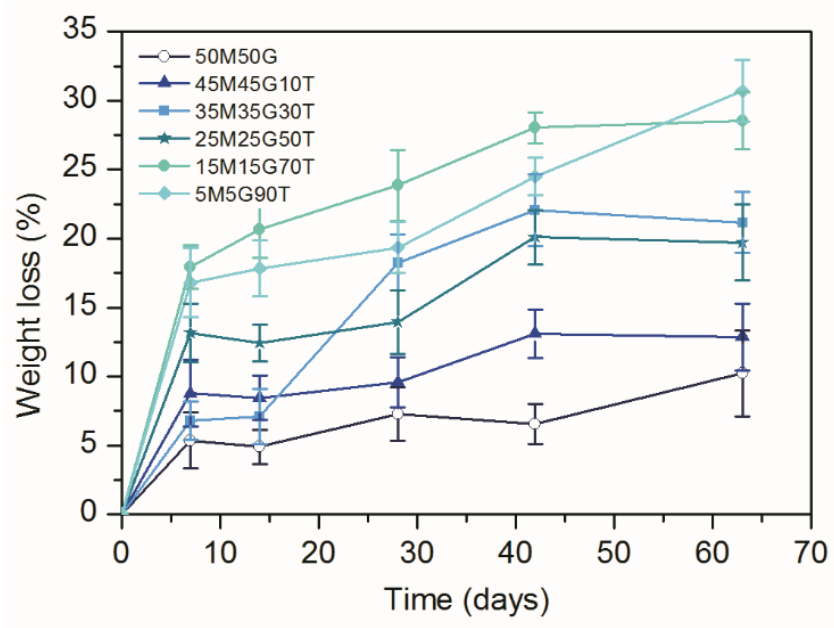

Fig. 9. Weight loss versus time during the hydrolytic degradation for 50M50G, 45M45G10T, 35M35G30T, 25M25G50T, 15M15G70T and 5M5G90T coatings. 
Incorporating TEOS to the sol-gel network increases the number of $\mathrm{Si}-\mathrm{O}-\mathrm{Si}$ bonds, as a result, the materials present higher degree of degradation after 63 days for higher TEOS content. For the case of 25M25G50T and 35M35G30T compositions, a similar response occurs (it should be noted that error bars overlap). Coatings with a $10 \%$ TEOS showed a $12.88 \%$ weight loss after 62 days of exposure to water, this degree of degradation is just slightly higher than 50M50G material, which showed a $10.22 \%$ value, so the variation is not significant. However, both 35M35G30T and 25M25G50T coatings show a similar rate of degradation (around $20 \%$ ) after 62 days, whereas compositions 15M15G70T and 5M5G90T reached values of weight loss around $30 \%$ after 62 days in contact with water. These higher variations respect to the 50M50G material can be more beneficial if higher release kinetics is needed.

\section{Discussion}

Hybrid sol-gel materials from the triple mixture of alcoxysilanes: MTMOS, GPTMS and TEOS were successfully synthesized. Furthermore, it has been possible to obtain homogeneous, transparent and well adhered coatings to the metal substrate, showing adequate properties for implants handling requirements. Sol-gel network condensation process has been demonstrated using ${ }^{29} \mathrm{Si}$ solid NMR (Fig. 1). Thus, the chemical characterization showed that the addition of TEOS promotes the sol-gel reticulation of MTMOS and GPTMS molecules, probably due to the small size and higher functionality of TEOS molecules, which favor the access and binding to the silicon atomic positions that do not react in the 50M50G composition. However, when the percentage of TEOS is higher than $30 \%$, it becomes more difficult to reach these free positions for condensation and the cross-linking becomes slightly lower.

It should be mentioned that despite the lower curing temperature of 45M45G10T with respect to 50M50G (see Table 2), a higher degree of condensation is obtained for 45M45G10T. This shows that the differences observed in the NMR results have a minor dependency on the curing temperature and are more significantly influenced by composition. FT-IR results corroborate that the condensation reactions have been properly produced and the Si-O-Si network successfully formed, demonstrating the feasibility of the sol-gel process in all cases. As can be seen in Fig. 2, the processing has been able to incorporate organic moieties in the structure, and the integrity of these functional groups has been maintained.

Contact angle results (Fig. 3) show that the moderate addition of TEOS to the sol-gel network increases hydrophilicity, reaching the maximum hydrophilic behavior for the $30 \%$ TEOS composition. After that, a higher percentage of TEOS in the composition supposes an increase of contact angle. This behavior is not completely understood and further experiments should be needed for a clear understanding. However, we believe that the initial increase in hydrophilicity could be due to the opening of the GPTMS epoxy rings, which produces an increase of silanol groups in the structure [18], and is enhanced by the presence of TEOS. Nevertheless, despite the further increase of TEOS content, a decrease of hydrophility takes place due to the more dominant reduction of GPTMS species. Hydrophilicity values are important for the cells behavior and the values found are in the optimal range $\left(60^{\circ}-90^{\circ}\right)$ for an adequate cell attachment $[34,35]$. Furthermore, a maximum roughness value was measured for the composition 35M35G30T.The biomaterial surface roughness is a critical parameter to obtain suitable tissue regeneration. Wirth et al. found in cell culture with rat osteoblasts that cell proliferation activity is modulated by roughness [36]. Consequently, it 
is possible to produce a better bone fixation with rough surfaces than employing smooth surfaces [37]. Hence, the coating with $30 \%$ TEOS is the material with the most suitable roughness.

EIS tests show that the impedance values decrease when TEOS is added in the sol-gel network (Fig. 5). This behavior was reported before in VTES:TEOS coatings [11] and for MTMOS:TEOS materials [14]. From the analysis of Rcoat and CPEcoat parameters (Fig. 7), it has been clearly shown that the presence of TEOS in the material reduces its capability as a protective coating, but increases its degradability. Furthermore, weight loss results (Fig. 9) are in agreement with the EIS results. Thus, 50M50G sol-gel network has the lowest rate of degradation from the weight loss analysis, which is in agreement with the higher pore resistance and lower capability of water absorption observed by EIS. Moreover, the higher degradability of coatings with more TEOS can be due to the increase of the porosity and the presence of higher quantities of water in the coatings. Since hydrolytic degradation of these sol-gel networks leads to the release of Si compounds with positive properties on bone regeneration [19], this behavior is considered crucial for the purpose of these coatings.

Therefore, for applications in implants, a compromise between degradation (silicon release) and protection of the metal during the early stages of the curing process is very important. In this work, it has been demonstrated that the use of different compositions allows tuning the balance between the adequate protective character and the gradual coating degradation kinetics. Finally, considering all the results obtained, the materials with $30 \%$ and $50 \%$ TEOS show an interesting intermediate compromise between degradation and protection. Besides, as 35M35G30T coating showed the highest roughness, it could be a good candidate for being used in the proposed application too. However, in a next step, biological assessments will be needed to shed more light on what is the optimal composition as biomaterial.

\section{Conclusions}

In this study it was possible to obtain homogeneous and well bonded hybrid coatings from a triple mixture of alkoxysilanes by the sol-gel technique, achieving high degrees of condensation. Furthermore, it has been found by electrochemical impedance spectroscopy and hydrolytic degradation tests that the variation of TEOS percentage in the composition allows regulating the degradation of the material without impairing other properties such as wettability. Adding TEOS to the reference composition (50\% GTPMS and $50 \%$ MTMOS) improved the roughness of the material. These results suggest that the increment achieved in the degradation could significantly improve the in vivo behavior of the reference composition 50M50G, and coatings with this new series of materials could be used in metal implants to improve their osseointegration. As the next step in this work, testing these materials in biological assays will be very interesting to confirm their promising properties.

\section{Acknowledgments}

The financial support of MAT2014-51918-C2-2-R, P11B2014-19 and Plan de Promoción de la Investigación from the Universitat Jaume I (Predoc/2014/25) is gratefully acknowledged. J. GarcíaCañadas acknowledge financial support from Ramón y Cajal programme (RYC-2013-13970). The experimental support of Raquel Oliver Valls and José Ortega Herreros is also acknowledged. 


\section{References}

[1] S. Prasad, M. Ehrensberger, M.P. Gibson, H. Kim, E.A. Monaco, Biomaterial properties of titanium in dentistry, J. Oral Biosci. 57 (2015) 192-199. doi:10.1016/j.job.2015.08.001.

[2] D.G. Olmedo, D.R. Tasat, G. Duffó, M.B. Guglielmotti, R.L. Cabrini, The issue of corrosion in dental implants: a review., Acta Odontol. Latinoam. 22 (2009) 3-9. http://www.scopus.com/inward/record.url?eid=2-s2.0-70349258115\&partnerID=tZOtx3y1.

[3] A. Arys, C. Philippart, N. Dourov, Y. He, Q.T. Le, J.J. Pireaux, Analysis of titanium dental implants after failure of osseointegration: combined histological, electron microscopy, and X-ray photoelectron spectroscopy approach., J. Biomed. Mater. Res. 43 (1998) 300-12. doi:10.1002/(SICI)1097-4636(199823)43:3<300::AID-JBM11>3.0.CO;2-J.

[4] S. Omar, F. Repp, P.M. Desimone, R. Weinkamer, W. Wagermaier, S. Ceré, J. Ballarre, Sol-gel hybrid coatings with strontium-doped 45S5 glass particles for enhancing the performance of stainless steel implants: Electrochemical, bioactive and in vivo response, J. Non. Cryst. Solids. 425 (2015) 1-10. doi:10.1016/j.jnoncrysol.2015.05.024.

[5] L.E. Amato, D. a. López, P.G. Galliano, S.M. Ceré, Electrochemical characterization of sol-gel hybrid coatings in cobalt-based alloys for orthopaedic implants, Mater. Lett. 59 (2005) 2026-2031. doi:10.1016/j.matlet.2005.02.010.

[6] J. Gallardo, P. Galliano, A. Durán, Bioactive and protective sol-gel coatings on metals for orthopaedic prostheses, J. Sol-Gel Sci. Technol. 21 (2001) 65-74. doi:10.1023/A:1011257516468.

[7] M. Martínez-Ibáñez, M.J. Juan-Díaz, I. Lara-Saez, A. Coso, J. Franco, M. Gurruchaga, J. Suay Antón, I. Goñi, Biological characterization of a new silicon based coating developed for dental implants., J. Mater. Sci. Mater. Med. 27 (2016) 80. doi:10.1007/s10856-016-5690-9.

[8] R.M. Pilliar, Surface Coating and Modification of Metallic Biomaterials, Surf. Coat. Modif. Met. Biomater. (2015) 185-217. doi:10.1016/B978-1-78242-303-4.00006-5.

[9] N.C. Rosero-Navarro, S. a. Pellice, Y. Castro, M. Aparicio, a. Durán, Improved corrosion resistance of AA2024 alloys through hybrid organic-inorganic sol-gel coatings produced from sols with controlled polymerisation, Surf. Coatings Technol. 203 (2009) 1897-1903. doi:10.1016/j.surfcoat.2009.01.019.

[10] G. Schottner, Hybrid sol-gel-derived polymers: Applications of multifunctional materials, Chem. Mater. 13 (2001) 3422-3435. doi:10.1021/cm011060m.

[11] M. Hernández-Escolano, M. Juan-Díaz, M. Martínez-Ibáñez, a. Jimenez-Morales, I. Goñi, M. Gurruchaga, J. Suay, The design and characterisation of sol-gel coatings for the controlled-release of active molecules, J. Sol-Gel Sci. Technol. 64 (2012) 442-451. doi:10.1007/s10971-012-2876-6. 
[12] D. Arcos, M. Vallet-Regí, Sol-gel silica-based biomaterials and bone tissue regeneration., Acta Biomater. 6 (2010) 2874-88. doi:10.1016/j.actbio.2010.02.012.

[13] M. Catauro, F. Bollino, F. Papale, C. Ferrara, P. Mustarelli, Silica-polyethylene glycol hybrids synthesized by sol-gel: Biocompatibility improvement of titanium implants by coating, Mater. Sci. Eng. C. 55 (2015) 118-125. doi:10.1016/j.msec.2015.05.016.

[14] M.J. Juan-Díaz, M. Martínez-Ibáñez, M. Hernández-Escolano, L. Cabedo, R. Izquierdo, J. Suay, M. Gurruchaga, I. Goñi, Study of the degradation of hybrid sol-gel coatings in aqueous medium, Prog. Org. Coatings. 77 (2014) 1799-1806. doi:10.1016/j.porgcoat.2014.06.004.

[15] M. Manzano, V. Aina, C.O. Areán, F. Balas, V. Cauda, M. Colilla, M.R. Delgado, M. Vallet-Regí, Studies on MCM-41 mesoporous silica for drug delivery: Effect of particle morphology and amine functionalization, Chem. Eng. J. 137 (2008) 30-37. doi:10.1016/j.cej.2007.07.078.

[16] L. Guo, W. Feng, X. Liu, C. Lin, B. Li, Y. Qiang, Sol-gel synthesis of antibacterial Hybrid Coatings on titanium, Mater. Lett. (2015) MLBLUED1503211. doi:10.1016/j.matlet.2015.08.027.

[17] H.-J. Jeon, S.-C. Yi, S.-G. Oh, Preparation and antibacterial effects of Ag-SiO2 thin films by solgel method, Biomaterials. 24 (2003) 4921-4928. doi:10.1016/S0142-9612(03)00415-0.

[18] M.J. Juan-Díaz, M. Martínez-Ibáñez, I. Lara-Sáez, S. da Silva, R. Izquierdo, M. Gurruchaga, I. Goñi, J. Suay, Development of hybrid sol-gel coatings for the improvement of metallic biomaterials performance, Prog. Org. Coatings. (2016). doi:10.1016/j.porgcoat.2016.01.019.

[19] E.M. Carlisle, Silicon: A possible factor in bone calcification, Science (80-. ). 167 (1970) 279-280. http://www.scopus.com/inward/record.url?eid=2-s2.0-0014951015\&partnerID=tZOtx3y1.

[20] A.M. Pietak, J.W. Reid, M.J. Stott, M. Sayer, Silicon substitution in the calcium phosphate bioceramics, Biomaterials. 28 (2007) 4023-4032. doi:10.1016/j.biomaterials.2007.05.003.

[21] A.F. Khan, M. Saleem, A. Afzal, A. Ali, A. Khan, A.R. Khan, Bioactive behavior of silicon substituted calcium phosphate based bioceramics for bone regeneration, Mater. Sci. Eng. C. 35 (2014) 245-252. doi:10.1016/j.msec.2013.11.013.

[22] J. Ballarre, D.A. López, W.H. Schreiner, A. Durán, S.M. Ceré, Protective hybrid sol-gel coatings containing bioactive particles on surgical grade stainless steel: Surface characterization, Appl. Surf. Sci. 253 (2007) 7260-7264. doi:10.1016/j.apsusc.2007.03.007.

[23] J. Méndez-Vivar, A. Mendoza-Bandala, Spectroscopic study on the early stages of the polymerization of hybrid TEOS-RSi (OR')3 sols, J. Non. Cryst. Solids. 261 (2000) 127-136. doi:10.1016/S0022-3093(99)00605-5.

[24] H. Aguiar, J. Serra, P. González, B. León, Structural study of sol-gel silicate glasses by IR and Raman spectroscopies, J. Non. Cryst. Solids. $355 \quad$ (2009) 475-480. 
doi:10.1016/j.jnoncrysol.2009.01.010.

[25] L.B. Capeletti, I.M. Baibich, I.S. Butler, J.H.Z. dos Santos, Infrared and Raman spectroscopic characterization of some organic substituted hybrid silicas., Spectrochim. Acta. A. Mol. Biomol. Spectrosc. 133 (2014) 619-25. doi:10.1016/j.saa.2014.05.072.

[26] A.M. Cabral, R.G. Duarte, M.F. Montemor, M.G.S. Ferreira, A comparative study on the corrosion resistance of AA2024-T3 substrates pre-treated with different silane solutions: Composition of the films formed, Prog. Org. Coatings. 54 (2005) 322-331. doi:10.1016/j.porgcoat.2005.08.001.

[27] K. a. Yasakau, J. Carneiro, M.L. Zheludkevich, M.G.S. Ferreira, Influence of sol-gel process parameters on the protection properties of sol-gel coatings applied on AA2024, Surf. Coatings Technol. 246 (2014) 6-16. doi:10.1016/j.surfcoat.2014.02.038.

[28] J. Ballarre, D. a. López, N.C. Rosero, A. Durán, M. Aparicio, S.M. Ceré, Electrochemical evaluation of multilayer silica-metacrylate hybrid sol-gel coatings containing bioactive particles on surgical grade stainless steel, Surf. Coatings Technol. 203 (2008) 80-86. doi:10.1016/j.surfcoat.2008.08.005.

[29] M. Puig, L. Cabedo, J.J. Gracenea, a. Jiménez-Morales, J. Gámez-Pérez, J.J. Suay, Adhesion enhancement of powder coatings on galvanised steel by addition of organo-modified silica particles, Prog. Org. Coatings. 77 (2014) 1309-1315. doi:10.1016/j.porgcoat.2014.03.017.

[30] S.J. García, J. Suay, Optimization of deposition voltage of cataphoretic automotive primers assessed by EIS and AC/DC/AC, Prog. Org. Coatings. 66 (2009) 306-313. doi:10.1016/j.porgcoat.2009.08.012.

[31] S.J. García, J. Suay, Application of electrochemical techniques to study the effect on the anticorrosive properties of the addition of ytterbium and erbium triflates as catalysts on a powder epoxy network, Prog. Org. Coatings. 57 (2006) 273-281. doi:10.1016/j.porgcoat.2006.09.008.

[32] M. Puig, L. Cabedo, J.J. Gracenea, J.J. Suay, The combined role of inhibitive pigment and organomodified silica particles on powder coatings: Mechanical and electrochemical investigation, Prog. Org. Coatings. 80 (2015) 11-19. doi:10.1016/j.porgcoat.2014.11.014.

[33] V.H.V. Sarmento, M.G. Schiavetto, P. Hammer, A.V. Benedetti, C.S. Fugivara, P.H. Suegama, S.H. Pulcinelli, C.V. Santilli, Corrosion protection of stainless steel by polysiloxane hybrid coatings prepared using the sol-gel process, Surf. Coatings Technol. 204 (2010) 2689-2701. doi:10.1016/j.surfcoat.2010.02.022.

[34] P.B. van Wachem, T. Beugeling, J. Feijen, A. Bantjes, J.P. Detmers, W.G. van Aken, Interaction of cultured human endothelial cells with polymeric surfaces of different wettabilities, Biomaterials. 6 (1985) 403-408. doi:10.1016/0142-9612(85)90101-2.

[35] C.P. Stallard, K.A. McDonnell, O.D. Onayemi, J.P. O’Gara, D.P. Dowling, Evaluation of protein 
adsorption on atmospheric plasma deposited coatings exhibiting superhydrophilic to $\begin{array}{llllll}\text { superhydrophobic } \quad \text { properties., } & \text { Biointerphases. } & 7 & \text { (2012) }\end{array}$ http://www.scopus.com/inward/record.url?eid=2-s2.0-84864093863\&partnerID=tZOtx3y1.

[36] C. Wirth, B. Grosgogeat, C. Lagneau, N. Jaffrezic-Renault, L. Ponsonnet, Biomaterial surface properties modulate in vitro rat calvaria osteoblasts response: Roughness and or chemistry?, Mater. Sci. Eng. C. 28 (2008) 990-1001. doi:10.1016/j.msec.2007.10.085.

[37] D. Buser, R.K. Schenk, S. Steinemann, J.P. Fiorellini, C.H. Fox, H. Stich, Influence of surface characteristics on bone integration of titanium implants. A histomorphometric study in miniature pigs, J. Biomed. Mater. Res. 25 (1991) 889-902. http://www.scopus.com/inward/record.url?eid=2s2.0-0025900565\&partnerID=tZOtx3y1. 